Lower-limb muscle function is a determinant of exercise tolerance after lung resection surgery in patients with lung cancer

Peer-reviewed author version

BURTIN, Chris; Franssen, Frits M. E.; Vanfleteren, Lowie E. G. W.; Groenen, Miriam T. J.; Wouters, Emiel F. M. \& SPRUIT, Martijn A. (2017) Lower-limb muscle function is a determinant of exercise tolerance after lung resection surgery in patients with lung cancer. In: RESPIROLOGY, 22(6), p. 1185-1189.

DOI: $10.1111 /$ resp.13041

Handle: http://hdl.handle.net/1942/24368 
Lower-limb muscle function is a determinant of exercise tolerance after lung resection surgery in patients with lung cancer

Chris Burtin, PT PhD ${ }^{1}$, Frits M.E. Franssen, MD PhD ${ }^{2,3}$, Lowie E.G.W. Vanfleteren, MD PhD ${ }^{2,3}$, Miriam T.J. Groenen, MSc ${ }^{2}$, Emiel F.M. Wouters, MD PhD²,3, Martijn A. Spruit, PT PhD ${ }^{1,2,4}$

${ }^{1}$ Faculty of Medicine and Life Sciences, Rehabilitation Research Centre, Biomedical Research Institute, Hasselt University, Diepenbeek, Belgium

${ }^{2}$ Department Research and Education, CIRO, center of expertise for chronic organ failure, Horn, The Netherlands

${ }^{3}$ Department of Respiratory Medicine, Maastricht University Medical Center (MUMC+), Maastricht, The Netherlands

${ }^{4}$ Department of Respiratory Medicine, Maastricht University Medical Centre, NUTRIM School of Nutrition and Translational Research in Metabolism, Maastricht, The Netherlands

Corresponding author:

Chris Burtin, PT PhD

Rehabilitation Research Centre, Biomedical Research Institute, Faculty of Medicine and Life Sciences, Hasselt University

Agoralaan Gebouw A, 3590 Diepenbeek, Belgium

chris.burtin@uhasselt.be

Word count abstract: $n=250$

Word count text: $n=1795$ 


\section{Summary at a glance}

We investigated determinants of exercise tolerance in lung cancer patients after resection surgery. This study is the first to identify quadriceps strength and quadriceps endurance capacity as a strong determinant of exercise tolerance in these patients, suggesting the need for routine lower-limb muscle function assessment and targeted interventions.

\section{Abstract}

Background and objective. This study aims to investigate the association between exercise tolerance, pulmonary function and lower-limb muscle function in patients with lung cancer that underwent lung resection surgery in the previous year.

Methods. Sixty-four patients (age $67 \pm 11$ years, 66\% male)performed a symptom-limited incremental cycle test to define peak oxygen consumption (VO2peak) and peak workload (Wpeak). The best of two six-minute walking distance (6MWD) tests was also included. Isometric quadriceps strength and isokinetic quadriceps endurance were measured. Postbronchodilator spirometry, lung volumes and diffusing capacity (DLCo) measurements were assessed. Univariate correlation analysis and multiple regression analyses were performed.

Results. VO2peak, Wpeak and 6MWD showed moderate to strong correlations with quadriceps strength/endurance and DLco while weak to moderate correlations were found with $\mathrm{FEV}_{1}, \mathrm{FRC}$ and body weight. Multiple regression showed that peak isometric quadriceps strength $(p<0.001)$ and DLco $(p<0.001)$ were significant predictors of $\mathrm{VO}_{2}$ peak (explained variance $R^{2}$ 0.67), while quadriceps endurance $(p=0.0015)$ and DLco $(p<0.0001)$ were 
significant predictors of $W$ peak $\left(R^{2} 0.61\right)$. Quadriceps endurance capacity $(p=0.013)$ but not DLco significantly contributed to the 6MWD model $\left(R^{2} 0.29\right)$.

Conclusions. We identified a strong significant relationship between peak aerobic capacity and quadriceps muscle function and lung diffusing capacity. Six-minute walking distance was significantly related to quadriceps muscle function but not to pulmonary function. These findings suggests that accurate assessment of lower-limb muscle strength has a role in the accurate interpretation of exercise tests and in selecting optimal candidates for resistance training interventions targeting the lower-limb muscles after resection surgery.

\section{Keywords}

Lung cancer - peak aerobic capacity - quadriceps endurance - quadriceps strength - six-minute walking distance

\section{Short title}

Exercise tolerance in lung cancer

\section{List of abbreviations}

$\mathrm{VO}_{2}$ peak: Peak oxygen consumption

W peak: Peak workload

6MWD: Six-minute walking distance

DLco: Diffusing capacity

$\mathrm{FEV}_{1}$ : Forced expiratory volume in one second

FVC: Forced vital capacity 


\section{Introduction}

Lung resection surgery is often the only available curative treatment option in patients with early stage lung cancer(1). After lung resection surgery, patients experience on average a $25 \%$ decrease in maximal exercise tolerance during the first months after surgery $(2,3)$. This decrease can partly be explained by a loss in ventilatory capacity. However, Granger et al. reported that exercise tolerance declines further during a period of six months following lung cancer treatment, in line with observed decreases in lower-limb muscle function and daily physical activity levels(4). These changes may be associated to the observed long-term increase in symptoms of fatigue and dyspnea and impairment of health-related quality of life in these patients $(5,6)$.

It is important to understand the physiological mechanisms leading to physical impairment in patients treated for lung cancer. Knowledge about the relative contribution of pulmonary function deficits and lower-limb muscle dysfunction could allow the development of individually tailored interventions aimed to improve exercise and functional capacity during and after cancer treatment.

Therefore, this cross-sectional study investigated the association between exercise tolerance, pulmonary function and lower-limb muscle function in patients with lung cancer after lung resection surgery. 


\section{Methods}

Data were collected as part of an standardized three-day multidisciplinary assessment in patients referred for comprehensive pulmonary rehabilitation at $\mathrm{ClRO}+$ (Horn, the Netherlands). Research ethical approval was not indicated because all of the tests were done as part of the routine initial assessment, and analyzed retrospectively. The Board of Directors of CIRO approved the use of de-identified patients' records.

\subsection{Patients}

All patients were referred for assessment based on clinical indication by their chest physician. Measurements were performed within one year after lung resection surgery. The exact time frame between surgery and assessment is not known due to ethical constraints. No formal exclusion criteria were used besides the inability to perform exercise and muscle function testing.

\subsection{Measurements}

Peak oxygen consumption ( $\mathrm{VO}_{2}$ peak) and peak workload ( $\mathrm{W}$ peak) were assessed using a symptom-limited incremental cycle test (Corival 400, Lode, Groningen, The Netherlands). Normative values published by Jones et al were used(7).

Patients performed two six-minute walking distance (6MWD) tests according to international guidelines(8); the best was used for analysis. Data were compared with normative values developed by Troosters et al(9).

Quadriceps strength was measured on a standardized dynamometer (Biodex Medical Corporation, Shirley, NY). Isometric strength was assessed by performing three 3-second maximal voluntary contractions. The highest peak torque was used for analysis. Isokinetic 
quadriceps function was assessed by performing 30 maximal repetitions at $90^{\circ} / \mathrm{s}$; peak torque values were calculated for every repetition. Isokinetic strength was defined as the average of the two highest peak torque values. Isokinetic endurance was defined as the total amount of work delivered during 30 repetitions. Normative values developed by Borges et al were used(10).

Routine post-bronchodilator spirometry, lung volumes and diffusing capacity (DLco) measurement were performed according to international recommendations $(11,12)$. The presence of chronic airflow limitation was determined by post-bronchodilator forced expiratory volume in one second $\left(\mathrm{FEV}_{1}\right) /$ forced vital capacity $(\mathrm{FVC})<0.7$.

Body weight was assessed to the nearest $0.1 \mathrm{~kg}$ using a calibrated weighing scale.

\subsection{Statistical analyses}

All statistical analyses were performed with SAS 9.4. Variables were expressed as mean \pm standard deviation (when continuous) or absolute number and proportion (when nominal). Univariate correlation analysis was performed using Pearson correlation coefficients and point biserial correlations (when assessing the relationship with gender). Multiple linear regression models were developed to estimate $\mathrm{VO}_{2}$ peak, $\mathrm{W}$ peak and 6MWD in 46 out of 64 patients (due to missing values of DLco). Age, gender, body weight, isometric quadriceps strength, isokinetic quadriceps strength, isokinetic quadriceps endurance, $\mathrm{FEV}_{1}$ and DLco were used as independent variables. When multicollinearity was present in the model (condition index > 30), highly related variables were identified and only the variable showing the highest univariate relationship with the dependent variable was included in the model(13). The level of significance was set at 0.05 for all statistical tests. 


\section{Results}

Seventy-four patients went through multidisciplinary assessment in our center. Sixty-four patients performed muscle testing and at least one exercise test (incremental cycle test or 6MWD test) and were included in the analysis. 6MWD $(n=1), W$ peak $(n=2), \mathrm{VO}_{2}$ peak $(n=7)$, spirometry values $(n=1)$ and $D L_{c o}(n=16)$ were not available in a subset of patients. All patients had non-small cell lung cancer. Patients underwent a lobectomy $(n=48)$, bi-lobectomy $(n=3)$ or pneumectomy $(n=13)$. Eleven patients received adjuvant chemotherapy, while three patients received combined adjuvant treatment (chemotherapy and radiotherapy). Baseline characteristics are summarized in Table 1 . Patients (age $67 \pm 11$ years, $66 \%$ male) showed a decreased FEV 1 (71 $\pm 21 \%$ pred) and diffusing capacity (DLco; $57 \pm 16 \%$ pred). On average, peak isometric quadriceps strength was slightly decreased ( $89 \pm 24 \%$ pred).

Maximal exercise tolerance during cycle ergometry was markedly decreased $\left(\mathrm{VO}_{2}\right.$ peak $70 \pm$ $26 \%$ pred; W peak $67 \pm 24 \%$ pred). Peak heart rate reached $84 \pm 13 \%$ of age-predicted maximal heart rate and peak ventilation equaled $70 \pm 19 \%$ of maximal voluntary ventilation. Borg scores at peak exercise were $7 \pm 2$ (dyspnea) and $5 \pm 3$ (leg fatigue). Oxygen saturation decreased from $97 \pm 1 \%$ at rest to $92 \pm 9 \%$ at peak exercise. Similarly, 6MWD was decreased to $75 \pm 17$ \%pred. Borg scores at the end of the test were $3 \pm 2$ (dyspnea) and $3 \pm 2$ (leg fatigue). Oxygen saturation decreased from $97 \pm 1 \%$ at rest to $92 \pm 5 \%$ at the end of the 6MWD test.

Table 2 includes correlation coefficients between absolute measures of exercise tolerance $\left(\mathrm{VO}_{2}\right.$ peak, W peak, 6MWD) and age, weight, quadriceps function and pulmonary function. $\mathrm{VO}_{2}$ peak, $\mathrm{W}$ peak and 6MWD show moderate to strong correlations with isometric and isokinetic quadriceps strength, quadriceps endurance capacity and DLco while weak to 
moderate correlations are found with FEV1, FRC (except for $\mathrm{VO}_{2}$ peak) and body weight (except for 6MWD). Isometric quadriceps strength, isokinetic quadriceps strength and isokinetic quadriceps endurance capacity show similar relationships with outcomes of exercise tolerance.

Multiple regression modeling shows that isometric quadriceps strength $(p<0.001)$ and DLco $(p<0.001)$ are significant predictors of $\mathrm{VO}_{2}$ peak (explained variance $\mathrm{R}^{2} 0.67$ ), while quadriceps endurance capacity $(p=0.0015)$ and DLco $(p<0.0001)$ are significant predictors of W peak $\left(R^{2}\right.$ 0.63). Quadriceps endurance capacity $(p=0.013)$ but not DLco significantly contributes to the 6MWD model ( $\left.R^{2} 0.37\right)$. Details of the regression models can be found in table 3 . 


\section{Discussion}

This study investigated to what extent exercise tolerance is related to muscle function and pulmonary function in patients that underwent lung resection surgery for lung cancer. We identified a strong significant relationship between $\mathrm{VO}_{2}$ peak and both quadriceps function and DLco. 6MWD was significantly related to quadriceps function but not to pulmonary function.

Exercise tolerance was markedly impaired in our patient sample (25-35\% of decrease compared to normative values in different measures). Granger et al. reported a similar decrease of $31 \%$ in six-minute walking distance in patients six months after lung resection surgery(4). Peak oxygen consumption was similar to findings of Nagamatsu et al. during the first months after surgery(3). The observed impairment in exercise tolerance is reported to be induced by the cancer treatment (including surgery and associated immobility), but to some extent deficits in exercise tolerance are likely to be apparent before surgery(2-4).

England et al. investigated different factors related to exercise performance during an incremental shuttle walking test in patients with incurable thoracic cancer(14). In line with our findings they identified a relationship between leg extensor power and exercise tolerance, but the strength of the relationship was rather weak $(r=0.39)$. The observed association between muscle function and exercise tolerance in patients with lung cancer is not surprising, as similar observations have been done previously in chronic lung and heart disease $(15,16)$. Even though average muscle function is only slightly reduced ( $89 \%$ of predicted isometric strength), the high accompanying standard deviation (25\%) suggests that large heterogeneity in muscle 
function exists across the patient sample. It is likely that muscle (dys)function plays an essential exercise-limiting role in a subset of patients (i.e. the weaker patients) while in other patients, pulmonary deficits might be more important to determine postoperative exercise tolerance. Unfortunately, our sample is too small to perform sub-analyses allowing further exploration of this hypothesis.

Interestingly, DLco is significantly related to $\mathrm{VO}_{2}$ peak (obtained during incremental cycling) but not to 6MWD. The former is in line with findings of Brunelli et al. showing that DLco is independently related to $\mathrm{VO}_{2}$ peak in postoperative lung cancer patients(17). The observation that submaximal self-paced walking exercise is less closely related to pulmonary function than maximal incremental cycle exercise is in line with observations in $\operatorname{COPD}(15)$, suggesting that deficits in pulmonary function are of less significance during submaximal exercise.

Gender and age were not related to measures of exercise tolerance. Even though surprising, this finding can be explained by the limited number of women and the homogenous distribution of age in our sample.

This study has some limitations that need to be addressed. Firstly, our data were collected as part of clinical routine and analyzed a posteriori. Consequently, it is difficult to reconstruct the exact reason underlying missing data. Nevertheless, all data were collected as part of a well standardized test battery, performed by experienced biometrists. The clinical setting of the assessment ensures that patients sampling was not biased by their willingness to participate in a clinical trial. Secondly, DLco measurements were only available in about $75 \%$ of included patients. As we considered this variable an important potential determinant of exercise tolerance, we decided to limit our multivariate analysis to patients with DLco measurement. However, our analysis appears to have sufficient power to provide an answer to the research 
question. Thirdly, our sample consists of patients who were referred for screening in light of a pulmonary rehabilitation program. Selection bias in favor of patients with impaired exercise tolerance and muscle function cannot be ruled out. Fourthly, the cross-sectional design does not allow interpretation whether the relationship between quadriceps function and exercise tolerance was already present prior to surgery. It would be interesting to know to what extent changes in muscle function after surgery boost the importance of muscle function as a determinant of exercise tolerance.

Given the use of $\mathrm{VO}_{2}$ peak as a screening tool to evaluate eligibility for surgical resection, the close relationship between quadriceps function and $\mathrm{VO}_{2}$ peak indicates that quadriceps function must be considered as an explaining variable in the interpretation of VO2 peak results in pre-operative screening. Furthermore, assessment of quadriceps function allows the identification of patients that would benefit from targeted resistance training interventions. This might be specifically relevant in settings where comprehensive evaluation of exercise tolerance (including cardiopulmonary exercise testing) is not feasible. Future research should confirm whether improved muscle function translates into enhanced maximal oxygen consumption in this subset of patients. 
1. Crino L, Weder W, van Meerbeeck J, Felip E, Group EGW. Early stage and locally advanced (nonmetastatic) non-small-cell lung cancer: ESMO Clinical Practice Guidelines for diagnosis, treatment and follow-up. Ann Oncol 2010; 21 Suppl 5: v103-115.

2. Bobbio A, Chetta A, Carbognani P, Internullo E, Verduri A, Sansebastiano G, Rusca M, Olivieri D. Changes in pulmonary function test and cardio-pulmonary exercise capacity in COPD patients after lobar pulmonary resection. Eur J Cardiothorac Surg 2005; 28: 754-758.

3. Nagamatsu Y, Maeshiro K, Kimura NY, Nishi T, Shima I, Yamana H, Shirouzu K. Long-term recovery of exercise capacity and pulmonary function after lobectomy. J Thorac Cardiovasc Surg 2007; 134: 1273-1278.

4. Granger CL, McDonald CF, Irving L, Clark RA, Gough K, Murnane A, Mileshkin L, Krishnasamy M, Denehy L. Low physical activity levels and functional decline in individuals with lung cancer. Lung Cancer 2014; 83: 292-299.

5. Solberg Nes L, Liu H, Patten CA, Rausch SM, Sloan JA, Garces YI, Cheville AL, Yang P, Clark MM. Physical activity level and quality of life in long term lung cancer survivors. Lung Cancer 2012; 77: 611-616.

6. Koczywas M, Williams AC, Cristea M, Reckamp K, Grannis FW, Jr., Tiep BL, Uman G, Ferrell B. Longitudinal changes in function, symptom burden, and quality of life in patients with earlystage lung cancer. Ann Surg Oncol 2013; 20: 1788-1797.

7. Jones NL, Makrides L, Hitchcock C, Chypchar T, McCartney N. Normal standards for an incremental progressive cycle ergometer test. Am Rev Respir Dis 1985; 131: 700-708.

8. ATS statement: guidelines for the six-minute walk test. Am J Respir Crit Care Med 2002; 166: 111117.

9. Troosters T, Gosselink R, Decramer M. Six minute walking distance in healthy elderly subjects. Eur Respir J 1999; 14: 270-274.

10. Borges $\mathrm{O}$. Isometric and isokinetic knee extension and flexion torque in men and women aged 2070. Scand J Rehabil Med 1989; 21: 45-53.

11. Miller MR, Hankinson J, Brusasco V, Burgos F, Casaburi R, Coates A, Crapo R, Enright P, van der Grinten CP, Gustafsson P, Jensen R, Johnson DC, Maclntyre N, McKay R, Navajas D, Pedersen OF, Pellegrino R, Viegi G, Wanger J. Standardisation of spirometry. Eur Respir J 2005; 26: 319338.

12. Maclntyre N, Crapo RO, Viegi G, Johnson DC, van der Grinten CP, Brusasco V, Burgos F, Casaburi R, Coates A, Enright P, Gustafsson P, Hankinson J, Jensen R, McKay R, Miller MR, Navajas D, Pedersen OF, Pellegrino R, Wanger J. Standardisation of the single-breath determination of carbon monoxide uptake in the lung. Eur Respir J 2005; 26: 720-735.

13. Callaghan KC, J. Revisiting the collinear data problem. Practical assessment, research and evaluation 2008; 13.

14. England R, Maddocks $M$, Manderson $C$, Wilcock $A$. Factors influencing exercise performance in thoracic cancer. Respir Med 2012; 106: 294-299.

15. Gosselink R, Troosters T, Decramer M. Peripheral muscle weakness contributes to exercise limitation in COPD. Am J Respir Crit Care Med 1996; 153: 976-980.

16. Senden PJ, Sabelis LW, Zonderland ML, van de Kolk R, Meiss L, de Vries WR, Bol E, Mosterd WL. Determinants of maximal exercise performance in chronic heart failure. Eur $J$ Cardiovasc Prev Rehabil 2004; 11: 41-47.

17. Brunelli A, Xiume F, Refai M, Salati M, Marasco R, Sciarra V, Sabbatini A. Evaluation of expiratory volume, diffusion capacity, and exercise tolerance following major lung resection: a prospective follow-up analysis. Chest 2007; 131: 141-147. 
Table 1 Patient characteristics.

\begin{tabular}{|c|c|c|}
\hline Variable & $\mathrm{N}$ & \\
\hline Age (yrs) & 64 & $67 \pm 11$ \\
\hline Male gender $(n(\%))$ & 64 & $42(66)$ \\
\hline Weight (kg) & 64 & $77 \pm 18$ \\
\hline BMI $\left(\mathrm{kg} / \mathrm{m}^{2}\right)$ & 64 & $26,5 \pm 4,8$ \\
\hline $\mathrm{FEV}_{1}(\mathrm{I})$ & 63 & $1,97 \pm 0,62$ \\
\hline $\mathrm{FEV}_{1}$ (\%pred) & 63 & $71 \pm 21$ \\
\hline FVC (\%pred) & 63 & $86 \pm 21$ \\
\hline $\mathrm{FEV}_{1} / \mathrm{FVC}$ & 63 & $66 \pm 12$ \\
\hline Obstructive disease $\left(\mathrm{FEV}_{1} / \mathrm{FVC}<0.7\right)$ & 63 & $39(61)$ \\
\hline FRC (\%pred) & 56 & $91 \pm 25$ \\
\hline DLCO (\%pred) & 46 & $57 \pm 16$ \\
\hline $\mathrm{VO}_{2}$ peak $(\mathrm{ml} / \mathrm{min})$ & 57 & $1303 \pm 377$ \\
\hline $\mathrm{VO}_{2}$ peak (\%pred) & 57 & $70 \pm 26$ \\
\hline W peak (\%pred) & 62 & $67 \pm 24$ \\
\hline 6-minute walking distance $(\mathrm{m})$ & 63 & $486 \pm 108$ \\
\hline 6-minute walking distance (\%pred) & 63 & $75 \pm 17$ \\
\hline Quadriceps isometric strength ( $\mathrm{Nm})$ & 64 & $132 \pm 40$ \\
\hline Quadriceps isometric strength (\% pred) & 64 & $89 \pm 24$ \\
\hline Quadriceps isokinetic strength ( $\mathrm{Nm})$ & 64 & $95 \pm 29$ \\
\hline Quadriceps isokinetic endurance (J) & 64 & $1720 \pm 596$ \\
\hline
\end{tabular}

Data are presented as mean \pm standard deviation or number (percentage). $\mathrm{N}=$ number of patients, yrs $=$ years, $\mathrm{BMI}=$ body mass index, $\mathrm{FEV}_{1}=$ forced expiratory volume in 1 second, \%pred = percentage of the predicted value, $F V C=$ forced vital capacity, $F R C=$ functional residual capacity, $D L C O=$ diffusing capacity, $\mathrm{VO}_{2}$ peak = peak oxygen consumption during an incremental cycle test, $\mathrm{W}$ peak = peak workload during an incremental cycle test, $\mathrm{Nm}=$ newtonmeter, $\mathrm{J}=$ Joule. 
Table 2 Simple correlation analysis.

\begin{tabular}{|c|c|c|c|}
\hline & $\mathrm{VO}_{2}$ peak & W peak & 6MWD \\
\hline Age & -0.03 & -0.13 & -0.14 \\
\hline Gender & 0.25 & 0.24 & 0.04 \\
\hline Weight & $0.53^{*}$ & $0.37^{*}$ & 0.20 \\
\hline Quadriceps isometric strength & $0.52^{*}$ & $0.64^{*}$ & $0.59^{*}$ \\
\hline Quadriceps isokinetic strength & $0.66^{*}$ & 0.72 & 0.60 \\
\hline Quadriceps endurance & $0.66^{*}$ & $0.74^{*}$ & $0.63^{*}$ \\
\hline FEV 1 & $0.43^{*}$ & $0.59^{*}$ & $0.46^{*}$ \\
\hline FRC & 0.17 & $0.29^{*}$ & $0.35^{*}$ \\
\hline DLco & $0.76^{*}$ & $0.72^{*}$ & $0.46^{*}$ \\
\hline
\end{tabular}

Data are Pearson correlation coefficients or point biserial correlations (gender); * indicates that the correlation is significant at the 0.05 level.

$\mathrm{VO}_{2}$ peak $=$ peak oxygen consumption during an incremental cycle test, $\mathrm{W}$ peak $=$ peak workload during an incremental cycle test, $6 \mathrm{MWD}=$ six-minute walking distance, $\mathrm{FEV}_{1}=$ forced expiratory volume in one second, $\mathrm{FRC}$

= functional residual capacity, DLco = diffusing capacity. 
Table 3. Multiple linear regression analysis

\begin{tabular}{|c|c|c|c|}
\hline Variable & Parameter Estimate & Standard Error & P-value \\
\hline \multicolumn{4}{|c|}{ VO2 peak model in $\mathrm{ml} / \mathrm{min}$ (adjusted $\mathrm{R}^{2} 0.67$ ) } \\
\hline $\mathrm{DLco}(\mathrm{mmol} / \mathrm{min} / \mathrm{kPa})$ & 147.67 & 24.32 & $<0.0001$ \\
\hline Quadriceps isometric strength $(\mathrm{Nm})$ & 2.28 & 1.05 & 0.036 \\
\hline Gender (male $=1$ ) & 129.68 & 109.75 & 0.24 \\
\hline Age (yrs) & -0.76 & 3.9 & 0.85 \\
\hline Intercept & 234.20 & 310.30 & 0.46 \\
\hline \multicolumn{4}{|c|}{ W max model in Watts (adjusted $R^{2} 0.63$ ) } \\
\hline $\mathrm{DLco}(\mathrm{mmol} / \mathrm{min} / \mathrm{kPa})$ & 8.91 & 2.32 & 0.0004 \\
\hline Quadriceps isokinetic endurance $(\mathrm{J})$ & 0.02 & 0.007 & 0.0041 \\
\hline Gender (male $=1$ ) & 14.12 & 7.94 & 0.083 \\
\hline Weight (kg) & -0.25 & 0.17 & 0.15 \\
\hline Age (yrs) & -0.41 & 0.32 & 0.22 \\
\hline Intercept & 52.72 & 23.79 & 0.033 \\
\hline \multicolumn{4}{|l|}{ 6MWD model in $\mathrm{m}$ (adjusted $\mathrm{R}^{2} 0.37$ ) } \\
\hline Quadriceps isokinetic endurance $(\mathrm{J})$ & 0.083 & 0.029 & 0.0069 \\
\hline Weight (kg) & -1.23 & 0.73 & 0.099 \\
\hline $\mathrm{DLco}(\mathrm{mmol} / \mathrm{min} / \mathrm{kPa})$ & 14.57 & 10.44 & 0.1708 \\
\hline Age (yrs) & -0.0067 & 1.39 & 0.99 \\
\hline Gender (male $=1$ ) & 0.089 & 33.61 & 0.99 \\
\hline Intercept & 378.62 & 101.35 & 0.0006 \\
\hline
\end{tabular}

$\mathrm{VO}_{2}$ peak $=$ peak oxygen consumption during an incremental cycle test, $\mathrm{DLco}=$ diffusing capacity, $\mathrm{mmol}=$ millimol, $\mathrm{kPa}=$ kilopascal, $\mathrm{Nm}=$ newtonmeter, yrs $=$ years, $\mathrm{J}=$ Joule, $\mathrm{W}$ peak $=$ peak workload during an incremental cycle test, $6 \mathrm{MWD}=$ six-minute walking distance. $\mathrm{P}$-value in bold: $\mathrm{p}<0.05$. 